\title{
Multiple-J mid-IR supercontinuum generation in quadratic nonlinear crystals
}

\author{
Bache, Morten; Zhou, Binbin; Ashihara, S.; Stingel, A.; Vanselous, H.; Petersen, P. B.
}

Published in:

Proceedings of the 41st International Conference on Infrared, Millimeter, and Terahertz waves (IRMMW-THz) 2016

Link to article, DOI:

10.1109/IRMMW-THz.2016.7758737

Publication date:

2016

Document Version

Peer reviewed version

Link back to DTU Orbit

Citation (APA):

Bache, M., Zhou, B., Ashihara, S., Stingel, A., Vanselous, H., \& Petersen, P. B. (2016). Multiple-J mid-IR supercontinuum generation in quadratic nonlinear crystals. In Proceedings of the 41st International Conference on Infrared, Millimeter, and Terahertz waves (IRMMW-THz) 2016 IEEE. International Conference on Infrared, Millimeter and Terahertz Waves https://doi.org/10.1109/IRMMW-THz.2016.7758737

\section{General rights}

Copyright and moral rights for the publications made accessible in the public portal are retained by the authors and/or other copyright owners and it is a condition of accessing publications that users recognise and abide by the legal requirements associated with these rights.

- Users may download and print one copy of any publication from the public portal for the purpose of private study or research.

- You may not further distribute the material or use it for any profit-making activity or commercial gain

- You may freely distribute the URL identifying the publication in the public portal 


\title{
Multiple- $\mu \mathrm{J}$ mid-IR supercontinuum generation in quadratic nonlinear crystals
}

\author{
M. Bache*, B.B. Zhou ${ }^{*}$, S. Ashihara ${ }^{\dagger}$, A. Stingel ${ }^{\ddagger}$, H. Vanselous ${ }^{\ddagger}$ and P. B. Petersen ${ }^{\ddagger}$ \\ *DTU Fotonik, Department of Photonics Engineering, Technical University of Denmark, Denmark \\ ${ }^{\dagger}$ Institute of Industrial Science, University of Tokyo, Japan \\ $\ddagger$ Department of Chemistry and Chemical Biology, Cornell University, USA
}

\begin{abstract}
Pumping a quadratic nonlinear crystal in the midIR we observe octave-spanning mid-IR supercontinua. A selfacting cascaded process leads to the formation of a self-defocusing nonlinearity, allowing formation of filament-free octave-spanning supercontinua in the 2.0-7.0 $\mu \mathrm{m}$ range with $10 \mathrm{~s}$ of $\mu \mathrm{J}$ pulse energies, much higher than filament-based techniques. This allows to use the supercontinuum as ultra-broadband excitation pulses in nonlinear optical applications.
\end{abstract}

$\mathbf{H}$ IGH-POWER mid-IR supercontinuum (SC) sources are needed to overcome the limited bandwidth from OPAtype schemes, for, e.g., femtosecond pump-probe spectroscopy of the fundamental frequencies of vibrational modes. They rely mainly on self-phase modulation (SPM) spectral broadening in bulk glasses or crystals [1]-[3], eventually limited by the onset of multiple filamentation due to the self-focusing nature of the SPM effect, and thus to few- $\mu$ J energies [?], [4]-[6]. Multicolor mixing in gases gives even more extreme bandwidths, but also much less mid-IR energy [7]-[10]. The challenge is to keep a high bandwidth and increase the power spectral density (PSD) so the SC source can be used as pump instead of probe.

Here we use a quadratic nonlinear crystal cut for strongly phase-mismatched second-harmonic generation (SHG), which allows us to flip the sign of the SPM effect so it becomes self-defocusing. This gives filamentation-free octave-spanning SC generation with much higher energies, as recently demonstrated in the near-IR [?], [11], [12]. Here we show that by pumping a mid-IR crystal, lithium thioindate $\left(\mathrm{LinS}_{2}\right.$, LIS), in the mid-IR close to its zero dispersion wavelength (ZDW), we get octave spanning SC generation with 10 s of $\mu \mathrm{J}$ pulse energies [13].

The LIS crystal was cut with $\theta=90^{\circ}$ and $\phi=0$. This gives a maximum quadratic nonlinearity $d_{\mathrm{eff}}=d_{33}=16 \mathrm{pm} / \mathrm{V}$ and makes the SHG strongly phase-mismatched $(\Delta k L \gg 2 \pi)$ leading to a self-defocusing cascading SPM-like nonlinearity $n_{2, \text { casc }} \propto-d_{\text {eff }}^{2} / \Delta k$ [13]. We pumped with 85 fs $50 \mu \mathrm{J}$ pulses in the 3.0-3.9 $\mu \mathrm{m}$ range from a commercial OPA and DFG system. The nearly transform-limited pulses were loosely focused $(0.27 \mathrm{~mm}$ FWHM) in the crystal. The output was measured with a spectrometer that used long-pass filters to selectively cover the 1-7 $\mu \mathrm{m}$ range. A typical power sweep is shown in Fig. 1 for $\lambda_{0}=3.60 \mu \mathrm{m}$, and the onset of an octavespanning SC was found at $150 \mathrm{GW} / \mathrm{cm}^{2}$. For the maximum intensity (using all the available pump energy) a flat $\mathrm{SC}$ is seen, extending beyond $6 \mu \mathrm{m}$. The SC process is fuelled by the cascading-induced self-defocusing SPM nonlinearity, self-

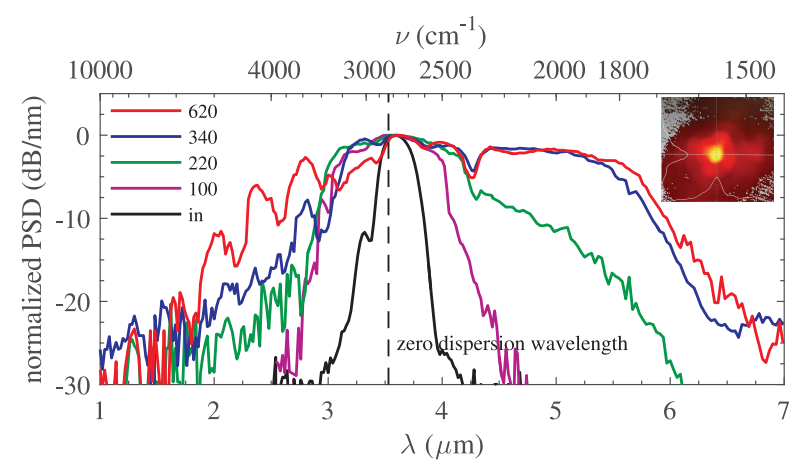

Fig. 1. SC generation in $15 \mathrm{~mm}$ LIS for $\lambda_{0}=3.60 \mu \mathrm{m}$ and sweeping the pump intensity (indicated in $\mathrm{GW} / \mathrm{cm}^{2}$ ). Inset: $\mathrm{SC}$ transverse mode profile.

steepening, soliton and dispersive wave formation below and above the ZDW, respectively. Importantly, most of the pump energy is retained in the SC. The inset shows the Gaussianlike transverse profile of the SC as measured with a mid-IR sensitive camera, indicating that the technique is filament free. Thus, expanding the pump spot size allows for using much higher pulse energies. We used the SC source as an excitation pulse in 2D mid-IR spectroscopy extended from the setup in [10] and in sum-frequency generation spectroscopy [14], where we were able to record spectra over a significantly broader bandwidth than with an OPA-based pump. This shows that the SC source has a high enough coherence, PSD and bandwidth to be used to pump a wide range of vibrational modes, and is therefore a vital next step in bright midIR SC sources. The technique can also be used in other mid-IR crystals as long as a defocusing nonlinearity can be realized [15], allowing various possibilities for pumping close to the ZDW in the short-wavelength mid-IR range, with the generated spectra extending potentially beyond $10 \mu \mathrm{m}$ with multiple- $\mu \mathrm{J}$ energies.

\section{REFERENCES}

[1] P. B. Corkum, P. P. Ho, R. R. Alfano, and J. T. Manassah, "Generation of infrared supercontinuum covering 3-14 $\mu \mathrm{m}$ in dielectrics and semiconductors," Opt. Lett., vol. 10, no. 12, pp. 624-626, 1985.

[2] S. Ashihara and Y. Kawahara, "Spectral broadening of mid-infrared femtosecond pulses in GaAs," Opt. Lett., vol. 34, pp. 3839-3841, 2009.

[3] J. J. Pigeon, S. Y. Tochitsky, C. Gong, and C. Joshi, "Supercontinuum generation from 2 to $20 \mu \mathrm{m}$ in GaAs pumped by picosecond $\mathrm{CO}_{2}$ laser pulses," Opt. Lett., vol. 39, no. 11, pp. 3246-3249, 2014. 
[4] F. Silva, D. Austin, A. Thai, M. Baudisch, M. Hemmer, D. Faccio, A. Couairon, and J. Biegert, "Multi-octave supercontinuum generation from mid-infrared filamentation in a bulk crystal," Nature Comms., vol. 3, p. 807, 2012

[5] H. Liang, P. Krogen, R. Grynko, O. Novak, C.-L. Chang, G. J. Stein, D. Weerawarne, B. Shim, F. X. Kärtner, and K.-H. Hong, "Threeoctave-spanning supercontinuum generation and sub-two-cycle selfcompression of mid-infrared filaments in dielectrics," Opt. Lett., vol. 40, no. 6, pp. 1069-1072, 2015.

[6] O. Mouawad, P. Béjot, F. Billard, P. Mathey, B. Kibler, F. Désévédavy, G. Gadret, J.-C. Jules, O. Faucher, and F. Smektala, "Mid-infrared filamentation-induced supercontinuum in As-S and an As-free Ge-S counterpart chalcogenide glasses," App. Phys. B, vol. 121, no. 4, pp. 433-438, 2015.

[7] T. Fuji and T. Suzuki, "Generation of sub-two-cycle mid-infrared pulses by four-wave mixing through filamentation in air," Opt. Lett., vol. 32, no. 22, pp. 3330-3332, 2007.

[8] P. B. Petersen and A. Tokmakoff, "Source for ultrafast continuum infrared and terahertz radiation," Opt. Lett., vol. 35, no. 12, pp. $1962-$ 1964, 2010.

[9] C. Calabrese, A. M. Stingel, L. Shen, and P. B. Petersen, "Ultrafast continuum mid-infrared spectroscopy: probing the entire vibrational spectrum in a single laser shot with femtosecond time resolution," Opt. Lett., vol. 37, pp. 2265-2267, 2012.

[10] A. M. Stingel, C. Calabrese, and P. B. Petersen, "Strong intermolecular vibrational coupling through cyclic hydrogen-bonded structures revealed by ultrafast continuum mid-IR spectroscopy," J. Phys. Chem. C, vol. 117, pp. 15 714-15 719, 2013.

[11] B. Zhou, H. Guo, and M. Bache, "Energetic mid-IR femtosecond pulse generation by self-defocusing soliton-induced dispersive waves in a bulk quadratic nonlinear crystal," Opt. Express, vol. 23, no. 5, pp. 6924-6936, 2015.

[12] B. Zhou and M. Bache, "Dispersive waves induced by self-defocusing temporal solitons in a beta-barium-borate crystal," Opt. Lett., vol. 40, no. 18 , pp. 4257-4260, 2015.

[13] — , "Invited article: Multiple-octave spanning high-energy mid-IR supercontinuum generation in bulk quadratic nonlinear crystals," $A P L$ Photonics, vol. 1, no. 5, p. 050802, 2016.

[14] H. Vanselous and P. B. Petersen, "Extending the capabilities of heterodyne-detected sum-frequency generation spectroscopy: Probing any interface in any polarization combination," J. Phys. Chem. C, vol. 120, no. 15 , pp. 8175-8184, 2016.

[15] M. Bache, H. Guo, and B. Zhou, "Generating mid-IR octave-spanning supercontinua and few-cycle pulses with solitons in phase-mismatched quadratic nonlinear crystals," Opt. Mater. Express, vol. 3, no. 10, pp. 1647-1657, 2013. 